\title{
Simplified Upper Airway Collapsibility Measurement for Uvulopalatopharyngoplasty (UPPP): Perspectives
}

\author{
Yoichi Nishimura ${ }^{1 *}$ and Alan R Schwartz ${ }^{2,3,4,5,6}$ \\ ${ }_{1}^{1}$ (Adjunct) Associate Professor, Department of Otorhinolaryngology, Teikyo University Chiba Medical Center, Chiba, Japan \\ ${ }^{2}$ (Adjunct) Professor, University of Pennsylvania Perelman School of Medicine, Philadelphia, PA, United States \\ ${ }^{3}$ Distinguished Visiting Professor, Universidad Peruana Cayetano Heredia, Lima, Peru \\ ${ }^{4}$ Scientific Advisor, Sleep and Breathing Technologies \\ ${ }^{5}$ Practitioner and Clinical Investigator, Pulmonary and Critical Care Associates of Baltimore, Baltimore, MD, United States \\ ${ }^{6}$ Professor (ret.), Johns Hopkins University, Baltimore, MD, United States
}

${ }^{*}$ Corresponding author: Yoichi Nishimura, Department of Otorhinolaryngology, Teikyo University Chiba Medical Center, 3426-3, Anesaki, Ichihara, Chiba, \#299-0111, Japan; Fax: +81-436-61-4773; Email: ny41west@yahoo.co.jp

Received: May 17, 2020; Accepted: May 25, 2020; Published: June 01, 2020

\section{Editorial}

Obstructive sleep apnea (OSA) syndrome is a highly prevalent disease, with an estimated prevalence of approximately $4 \%$ in men and $2 \%$ in women [1]. It is associated with significant morbidity and mortality that increases with age and its prevalence peaks at approximately 55 years of age in men [2]. Therefore, effective treatment of patients with OSA is critical. Unfortunately, treatments that bypass the airway, or simply open the pharyngeal airway are either morbid or unsuccessful, respectively. Uvulopalatopharyngoplasty (UPPP), since Fujita et al [3] first described as a surgical procedure in 1981, has been developed as a surgical approach for treating adults with OSA, with the aim of opening (dilating) the pharyngeal airway. It still remains the most common surgical procedure performed to treat adults with OSA, with an overall success rate of approximately $40 \%$ in unselected patients $[4,5]$. Therefore, OSA surgeons do not favor UPPP as a treatment of choice for all patients with OSA. UPPP could be effective, in appropriately selected patients, such as those with hypertrophic large tonsils, webbing of the posterior pillars, elongated and thickened uvulas, redundant pharyngeal folds and a normal tongue with a retro-displaced soft palate ("favorable" anatomic structures). OSA is characterized by upper airway collapse and/or occlusion during sleep, which mainly affects the middle pharyngeal area especially velopharyngeal and glossopharyngeal portions. Patients with OSA tend to have a more narrow middle pharyngeal space, smaller middle pharyngeal airway volume [6], that is characterized with the anatomical imbalance between the large volume of upper airway contents (i.e., tonsils and surrounding soft-tissues) and small volume of container (i.e., craniofacial bony structures) (Anatomical balance theory) [7] . This means if patients have a large volume of soft tissue content and/or small container volume, the residual pharyngeal air space might result in crowding and stuffing, which may cause airway occlusion during sleep. In applying this theory to sleep surgery, OSA surgeons often try to reduce the soft tissue contents and/or dilate the bony container surrounding the pharyngeal airway, which should increase airway volume and enlarge the pharyngeal airway. UPPP is designed to resect large hypertrophic tonsils, removing the redundant excessive distal palatal tissue. It will dilate the airway lumen at the level of velopharyngeal area, which is expected to increase upper airway volume. It is not clear, however, why UPPP does not always increase upper airway volume as the OSA surgeon anticipates. Recently, the changes in velopharyngeal and glossopharyngeal airway morphology and volume after UPPP were examined in adult patients with OSA and bilateral large tonsils by three-dimensional computed tomography [8]. In this paper, morphology of the glossopharyngeal airway was compared before and after UPPP. In their three cases, patients' apnea-hypopnea indices and daytime sleepiness had improved dramatically after UPPP, but interestingly enough, they found that the glossopharyngeal airway clearly dilated after UPPP, although the volume changes in the velopharyngeal and glossopharyngeal airways were negligible.

Just imagine two $250 \mathrm{ml}$ coca-cola or pepsi bottles, one is made of plastic and the other is made of aluminum. Consider their characteristics: is the crushability (collapsibility) of those two bottles equal? As we imagined, even if the size of two empty coca-cola or pepsi containers is the same, the plastic bottle is crushable and aluminum can might be quite stiff. Even a plastic bottle of $500 \mathrm{ml}$ would be easy to dent, whereas an aluminum can of similar or even smaller size would be hard to crush or collapse. Thus, the ultimate size of the airway impacts less on the success of surgery than the change in its mechanical properties (stiffness or collapsibility). It is worth recalling that OSA is characterized by upper airway collapse and/or occlusion during respiration and sleep, which is not static but dynamic phenomenon. Treating OSA is complicated, of course. Dilating of the upper airway might be necessary yet insufficient to open the upper airway. To be sure, dilating a small airway might be an important treatment component of therapy, but it might not be the main goal of therapy. Even if the airway becomes wide and dilated post-operatively, if it is still soft and collapsible (and easy to dent), the airway will dynamically collapse and/or occlude very easily during sleep. In a similar vein, just imagine a rubber band, when stretched (dilated), it will become stiff or even 
rigid and less collapsible. It is possible that when we dilate (stretch) the patient's pharyngeal airway with a UPPP procedure, it could become less collapsible. But anatomic factors (i.e., small airway) may not be the only reason a patient has OSA. Instead, a dynamic phenomenon (i.e., respiration and sleep), airway characteristics (i.e., not easy to dent), airway stiffness (collapsibility) must be also considered in evaluating the airway and the potential effects of surgery. It is likely that airway dilation (with a concomitant increase in volume) is not our primary surgical goal. Our goal must be to stabilize the upper airway (i.e., make it uncrushable: not easy to dent) against dynamic collapse that threatens its patency in patients with OSA. Whereas investigators have identified both anatomic and neuromuscular control factors that increase pharyngeal collapsibility during sleep in patients with OSA [9], a physiologic basis for measuring pharyngeal collapsibility (critical pressure: Pcrit) would be useful to evaluate in patients with OSA; the collapsibility of individuals with varying levels of pharyngeal airway obstruction during sleep could be examined before surgery; and the relationship between changes in pharyngeal collapsibility and changes in the severity of OSA before and after UPPP could be elucidated [10]. Evaluation of Pcrit pre-operatively for individual patients with OSA might help predict success in treating a patient. Despite the potential utility of Pcrit measurement, Pcrit cannot be easily measured, especially in the outpatient clinic or in the hospital ward. Such measurements should be facilitated in the outpatient clinic or in the hospital ward for individual OSA patients before and after surgery, as if it were simply a blood pressure measurement. Recently, a simple, novel non-invasive streamlined approach for measuring Pcrit was published [11]. Additional research to extend this approach to Pcrit measurements in prospective UPPP patients is warranted.

Keywords: Airway volume, Obstructive sleep apnea, Pcrit, Uvulopalatopharyngoplasty.

\section{References}

1. Young T, Palta M, Dempsey J, Skatrud J, Weber S et al. (1993) The occurrence of sleep- disordered breathing among middle-aged adults. N Engl J Med 328: 1230-1235. [crossref]

2. Bixler EO, Vgontzas AN, Ten Have T, Tyson K, Kales A (1998) Effects of age on sleep apnea in men: I. Prevalence and severity. Am J Respir Crit Care Med 157: 144-1488. [crossref]

3. Fujita S, Conway W, Zorick F, Roth T (1981) Surgical correction of anatomic abnormalities in obstructive sleep apnea syndrome: uvulopalatopharyngoplasty. Otolaryngol Head Neck Surg 89: 923-934. [crossref]

4. Sher AE, Schechtman KB, Piccirillo JF. (1996) The efficacy of surgical modifications of the upper airway in adults with obstructive sleep apnea syndrome. Sleep. 19: 156177. [crossref]

5. Senior BA, Rosenthal L, Lumley A, Gerhardstein R, Day R (2000) Efficacy of uvulopalatopharyngoplasty in unselected patients with mild obstructive sleep apnea. Otolaryngol Head Neck Surg 123: 179-182. [crossref]

6. Schwab RJ, Pasirstein M, Pierson R, Mackley A, Hachadoorian R et al. (2003) Identification of upper airway anatomic risk factors for obstructive sleep apnea with volumetric magnetic resonance imaging. Am J Respir Crit Care Med 168: 522-530. [crossref]

7. Watanabe T, Isono S, Tanaka A, Tanzawa H, Nishino T (2002) Contribution of body habitus and craniofacial characteristics to segmental closing pressures of the passive pharynx in patients with sleep-disordered breathing. Am J Respir Crit Care Med 165: 260-265. [crossref]

8. Nishimura Y, Fujii N, Yamamoto T, Hamed MA, Nishimura M et al. (2016) Volumes of Velopharyngeal and Glossopharyngeal Airway Were Not Changed after Uvulopalatopharyngoplasty: Report of Three Cases. Case Rep Otolaryngol. [crossref]

9. Patil SP, Schneider H, Schwartz AR, Smith PL (2007) Adult obstructive sleep apnea: pathophysiology and diagnosis. Chest 132:325-37. [crossref]

10. Schwartz AR, Schubert N, Rothman W, Godley F, Marsh B et al. (1992) Effect of uvulopalatopharyngoplasty on upper airway collapsibility in obstructive sleep apnea. Am Rev Respir Dis 145: 527-532. [crossref]

11. Nishimura Y, Arias RS, Pho H, Pham LV, Curado TF et al. (2018) A Novel Noninvasive Approach for Measuring Upper Airway Collapsibility in Mice. Front Neurol 9. [crossref]

\section{Citation:}

Yoichi Nishimura, Alan R Schwartz (2020) Simplified upper airway collapsibility measurement for uvulopalatopharyngoplasty (UPPP): Perspectives.. Otorhinolaryngol Hypersensitivity Treat Volume 1(1): 1-2. 